The Influence of Plutonium Concentration and Solution Flow Rate on the Effective Capacity of Macroporous Anion Exchange Resin 


\title{
THE INFLUENCE OF PLUTONIUM CONCENTRATION AND SOLUTION FLOW RATE ON THE EFFECTIVE CAPACITY OF MACROPOROUS ANION EXCHANGE RESIN
}

\author{
by
}

\author{
S. Fredric Marsh and Timothy D. Gallegos
}

\begin{abstract}
The principal aqueous process used to recover and purify plutonium at the Los Alamos Plutonium Facility is anion exchange in nitric acid. Previous studies with gel-type anion exchange resin have shown an inverse relationship between plutonium concentration in the feed solution and the optimum flow rate for this process. Because gel-type resin has been replaced with macroporous resin at Los Alamos, the relationship between plutonium concentration and solution flow rate was reexamined with the selected Lewatit MP-500-FK resin using solutions of plutonlum in nitric acid and in nitric acid with high levels of added nitrate salts. Our results with this resin differ significantly from previous data obtained with gel-type resin. Flow-rate variation from 10 to 80 liters per hour had essentially no effect on the measured quantities of plutonium sorbed by the macroporous resin. However, the effect of plutonium concentration in the feed solutions was pronounced, as feed solutions that contained the highest concentrations of plutonium also produced the highest resin loadings. The most notable effect of high concentrations of dissolved nitrate salts in these golutions was an increased resin capacity for plutonium at low flow rates.
\end{abstract}

\section{INTRODUCTION}

Anion exchange in nitric acid is the principal aqueous process used to recover and purify plutonium at Los Alamos. An important parameter that affects this process is the relationship between plutorium concentration and the optimal flow rate at which feed solution is supplied to the ion exchange column. It has long been accepted qualitatively that feed solutions of higher plutonium concentration should be loaded at lower flow rates. This premise is reflected in Fig. 1, copied from the "Los Alamos Standard Operating Procedure for Nitrate Anion Exchange." ${ }^{1}$ Unfortunately, the experimental data that support Fig. 1 are from studies of gel-type anion exchange resins no longer used.

A recently completed ion exchange development program at Los Alamos ${ }^{2}$ demonstrated that certain macroporous resins are much superior to gel-type resins for processing plutonium. Operational guidelines for plutonium processing based on past studies with gel-type resins have therefore become obsolete. For this reason, we designed an experimental system to measure the influence of plutonium concentration and feed-solution flow rate on the effective capacity of the preferred macroporous resin. The objective of this investigation was to define optimum flow rates for 


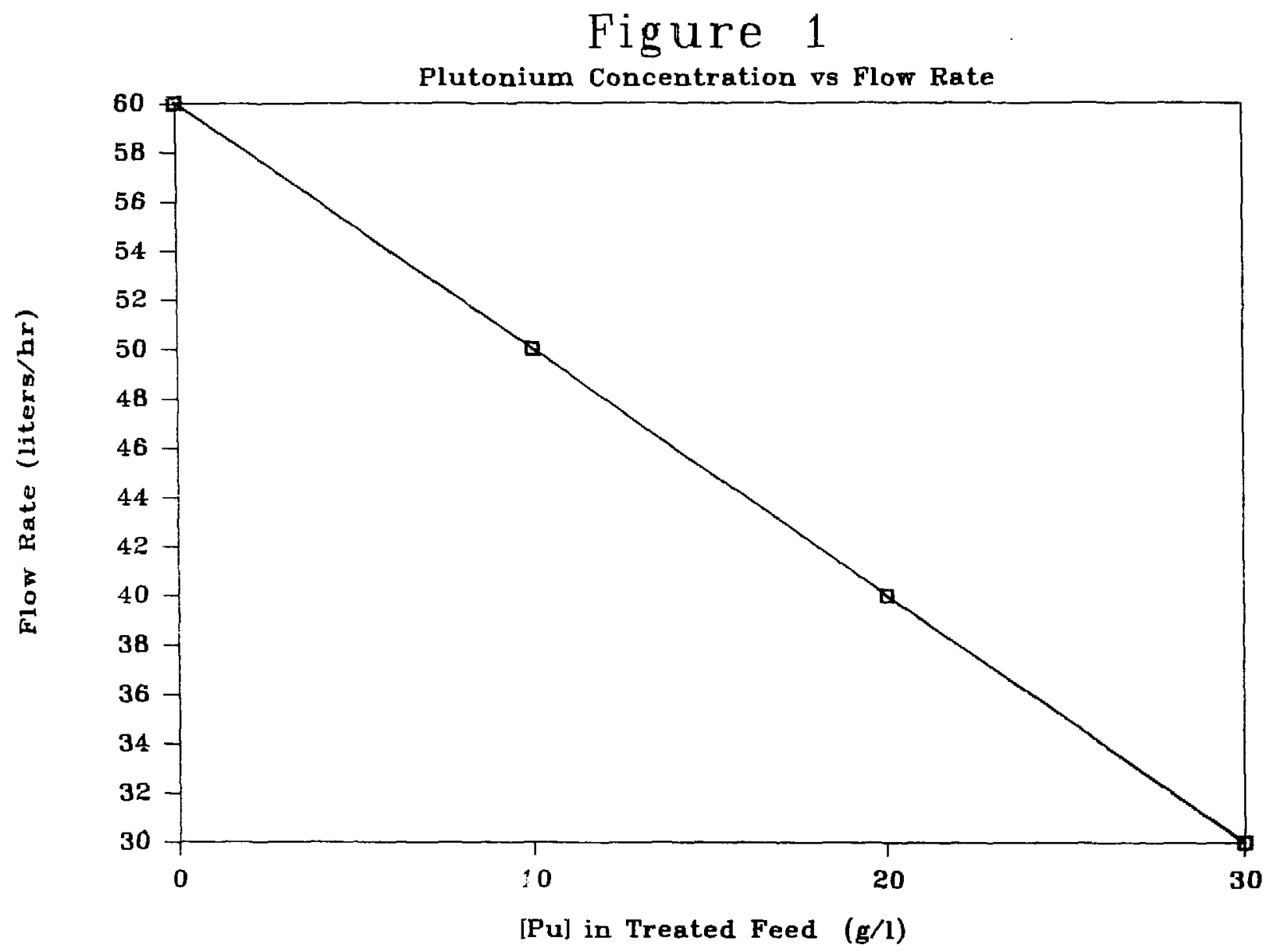

Fig. 1. Guide for plutonium concentration vs flow rate taken from the "Los Alamos Standard Operating Procedure for Nitrate Anion Exchange." 1

loading anion exchange columns of the selected resin with feed solutions of specified plutonium concentration and salt composition.

This study has produced valuable operational data for a superior macroporous resin that is gaining widespread acceptance within the nuclear industry. In addition to providing new guidelines that can improve process throughput and efficiency, these experimental results are of special interest because they differ significantly from those reported in previous studies of other resins. ${ }^{3,4}$

\section{EXPERIMENTAL}

All anion exchange resin used in this study was taken from a single batch of Lewatit MP-500-FK (40to 70 -mesh) resin that had been used ir routine processing at Los Alamos for nearly a year. We selected used resin because the performance of this resin improves significantly with repeated use, for reasons not yet fully understood. Because the thoroughly conditioned resin used in this study reliably represents the resin in production columns, the results reported here should apply quite directly to full-scale plant operations.

The complete study consisted of two separate phases. In Phase I we evaluated feed solutions that contained only plutonium in $7 M$ nitric acid, whereas in Phase II we evaluated feed solutions of high salt content that simulated recoverable waste from pyrochemical operations. Thus, the solutions tested bracketed the entire concentration range of impurities found in actual process feed solutions.

The master solution of plutonium nitrate, from which all other solutions were prepared, contained a fluoride-to-plutonium ratio of 0.072 . This base level of fluoride was present in Phase I solutions, to which no aluminum was added, and in Phase II solutions that contained additional fluoride and aluminum. The plutonium in the master solution was converted to $\mathrm{Pu}$ (IV) by adding hydrogen peroxide. ${ }^{5}$ After spectrophotometric analysis confirmed the absence of $\mathrm{Pu}(\mathrm{VI})$ and $\mathrm{Pu}$ (III), individual dilutions were prepared. 


\section{Phase I: Low-Salt Solutions}

Plutonium Concentration. The four selected feed-solution concentrations of approximately 10, 20, 50 , and 110 grams of plutonium per liter bracket typical plutonium concentrations of routine anion exchange processes at Los Alamos. The various plutonium concentrations used in this study were obtained by diluting a portion of an initial master solution that contained approximately 120 grams of plutonium per liter. Final solution volumes were approximately 15 , $6.25,2.5$, and 1.2 liters, respectively, for the four plutonium concentrations described above.

Flow Rates. The four flow rates of 10, 20,40, and 80 liters per hour for loading the feed solutions were likewise selected to bracket flow rates typically used in routine anion exchange processes at Los Alamos.

Nitric Acid. The concentration of nitric acid, held constant at $7 \mathrm{M}$ throughout the entire series of experiments, is the nominal acid concentration used in routine anion exchange processing.

Nitrate. In each solution, the constant concentration of nitrate in the form of nitric acid was supplemented by an additional amount of nitrate associated with the dissolved plutonium nitrate. We assumed that each $\mathrm{Pu}(\mathrm{IV})$ ion had four nitrate ions associated with it, although this assumption was not experimentally verified.

We recognized that $\mathrm{Pu}(\mathrm{IV})$ can associate with more than four nitrate ions and that such anionic nitrate species of plutonium existed in these solutions. Such anionic species must, however, be offset by an appropriate number of hydrogen ions to preserve overall charge balance. All hydrogen ions associated in this manner with anionic nitrato complexes were measured in the free-acid determination and therefore were included in the measured concentration of nitric acid.

Although the total quantity of plutonium was held constant in all experimental solutions, solutions of specified plutonium concentrations were prepared by diluting the uniform, initial quantity of plutonium to an appropriate final volume. If we assume four nitrate ions are contributed by each $\mathrm{Pu}(\mathrm{IV})$ ion, the additional ritrate concentrations would be $0.17,0.33,0.83$, and $2.00 \mathrm{M}$ for plutonium concentrations of $10,20,50$, and 120 grams per liter, respectively.

Column Loading Experiments. Sixteen separate experiments were performed to evaluate all combinations of the four plutonium concentrations with the iour selected flow rates. Experimental conditions were chosen to closely simulate actual anion exchange process operations, although the scale was reduced to minimize the quantity of plutonium, solutions, and glove-box space required.

The flash chromatography columns (J. T. Baker \#7022-6) used as anion exchange columns in our study (Fig. 2) are 24 inches high, ds are the full-scale anion exchange columns. However, the diameter of these chromatography columns is only 1.5 inches, which represents a 16-fold scale reduction from the 6-inch diameter of full-scale columns.

A measured volume of 600 milliliters of settled, wet resin added to each small-scale column resulted in a resin height of about 21 inches, which is comparable to the resin height in full-scale process columns.

\section{Phase II: High-Salt Solutions}

Appropriate quantities of salts were added to Phase II solutions to simulate pyrochemical operations waste solutions with concentrations of $0.69 \mathrm{M} \mathrm{Ca}\left(\mathrm{NO}_{3}\right)_{2}$, $0.76 \mathrm{M} \mathrm{Mg}\left(\mathrm{NO}_{3}\right)_{2}$, and $0.093 \mathrm{M} \mathrm{Al}\left(\mathrm{NO}_{3}\right)_{3}$.

Plutonium Concentration. Plutonium concentrations in Phase II solutions were essentially identical to those in Phase I solutions, with one exception. The highest concentration of plutonium (greater than 110 grams per liter) could not be attained in these high-salt solutions, which were already nearly saturated with nitrate salts. The plutonium concentrations in Phase II solutions therefore were limited to the three lower levels of 10, 20, and 50 grams per liter. These levels encompassed all realistic levels for high-salt solutions, however, because high-salt solutions from pyrochemical waste rarely contain high concentrations of plutonium.

Nitrate. Phase II solutions contained not only nitrate added as $7 \mathrm{M}$ nitric acid and nitrate ions associated with plutonium (as described under Phase I), but also nitrate ions introduced as calcium, magnesium, and aluminum nitrate salts. The total concentration of the nitrate added to Phase II solutions in the form of nitrate salts was $3.18 \mathrm{M}$.

Fluoride. High-salt, pyrochemical waste solutions encountered in an actual aqueous processing situation also contain significant amounts of fluoride. The exact amount of fluoride is unknown, however, because varying portions of the initial hydrofluoric acid are lost by volatilization during dissolution. A recent study at Los Alamos ${ }^{6}$ determined the effect of various levels of 


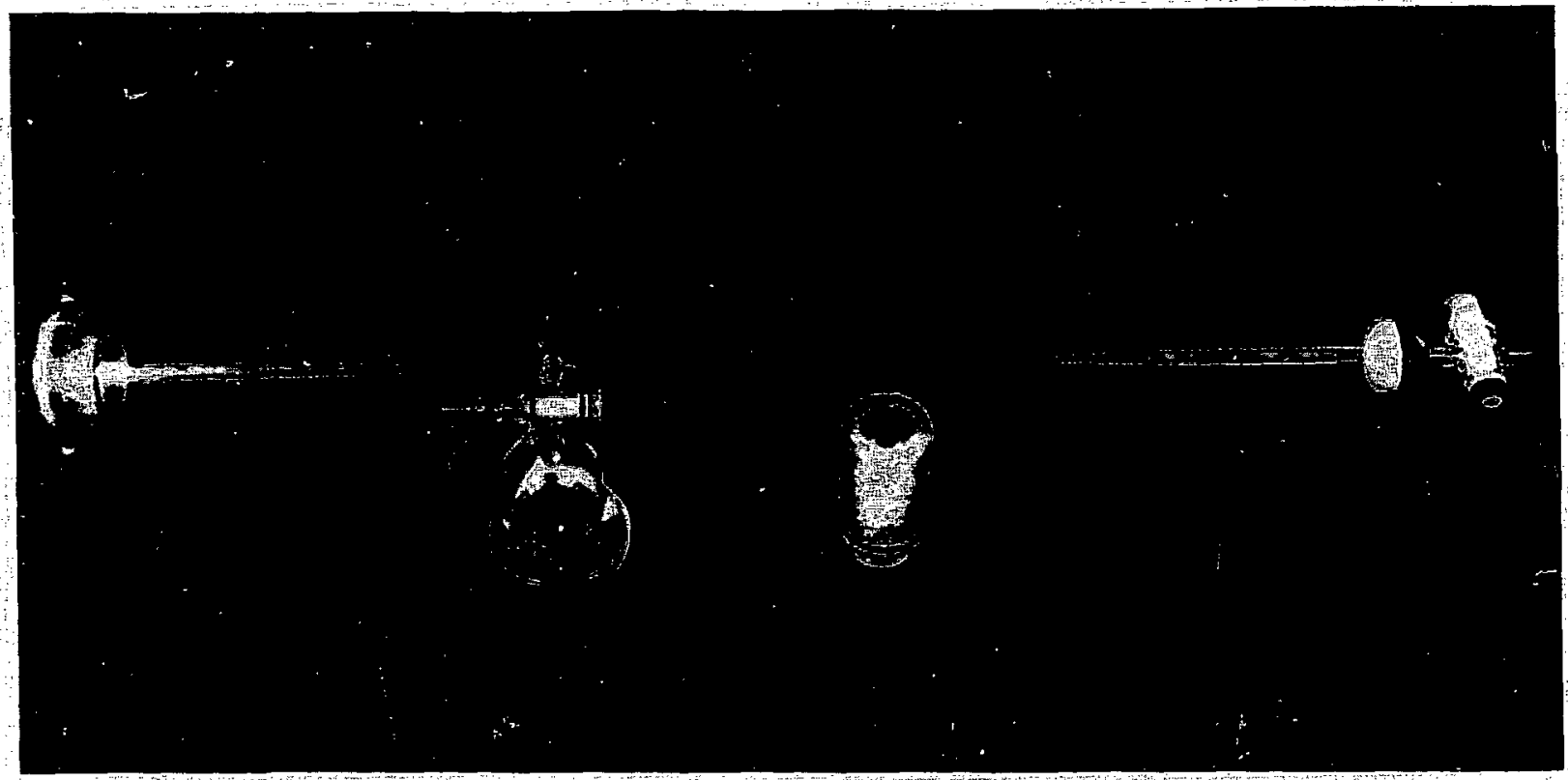

Flg. 2. Flash chromatography column used for one-sixteenth-scale anion exchange column studies.

fluoride and aluminum on the plutonium ion exchange process. Based on the recommendations of this study, the fluoride !evel in Phase II solutions was adjusted to $0.093 M$, to be equal to the concentration of aluminum.

\section{Experimental Procedure}

Experimental Setup. Figure 3 shows the experimental setup before its introduction into the glove box. After the installation of this apparatus in the glove box, each plutonium feed solution was prepared and thoroughly mixed in a 6-inch column designated for feed solution (Fig. 4). A peristaltic pump then transferred feed solutions to the anion exchange columns, as shown in Fig. 3, at preset flow rates. During the loading of each feed solution onto an anion exchange column (background of Fig. 5), the eftluent solution was collected and stored in a clean 6-inch column (foreground of Fig. 5) for subsequent analysis.

Resin Capacity at Saturation. The effective capacity of an anion exchange column may be defined in various ways. Some investigators have chosen to report the quantity of plutonium retained on the ion exchange column when the plutonium exiting the column (breakthrough) reaches predetermined levels of $1 \%,{ }^{7} 10 \%,{ }^{8}$ or even $5 \% \% .{ }^{3}$ We chose instead to determine the saturation capacity of the anion exchange column by loading each column with a volume of feed solution that contained an excess of plutonium. Although every experiment performed in this manner was subjected to different conditions of plutonium concentration and solution flow rate, the total quantity of plutonium was held constant.

The described column-saturation technique is considered to be reliable because the total quantity of plutonium always exceeded the maximum capacity of the anion exchange column by at least $20 \%$. The quantity of plutonium retained on the resin is, by definition, the difference between the quantity of plutonium in the initial feed solution and the quantity of plutonium in the effluent solution. We therefore elected to use the difference between these two measured values as a reliable measure of the quantity of plutonium retained on the column.

Because some portion of feed solution always remains in the column void space after the solution loading is complete, this by-difference measurement of sorbed plutonium is subject to bias. We recognized that a considerable amount of plutonium could remain in the resin void volume, which we measured to be approximately one-third of the total resin bed volume. Furthermore, the quantity of remaining plutonium would depend on the concentration of plutonium in the residual feed solution of that particular 


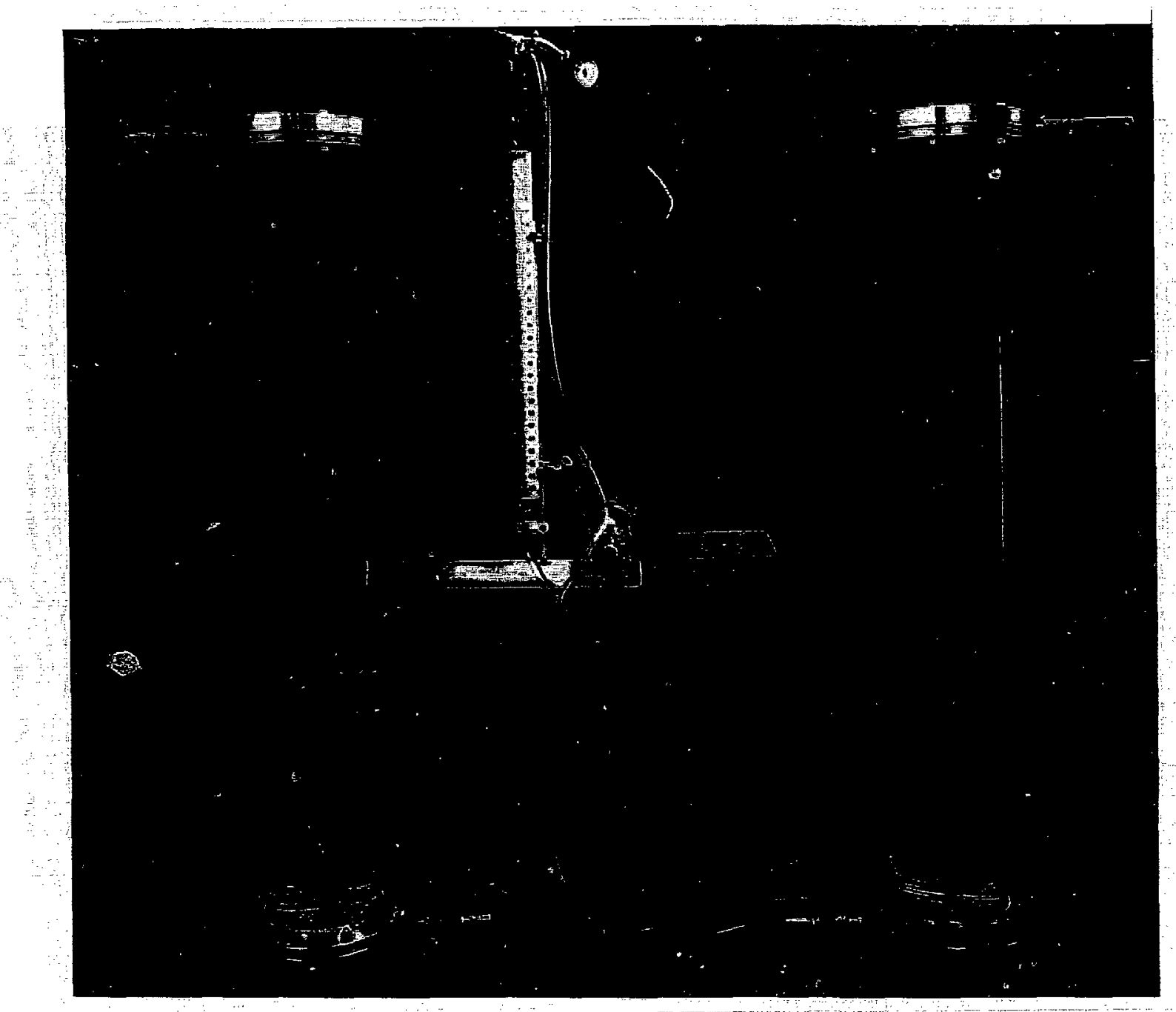

Flg. 3. Complete experimental setup, consisting of feed tank, peristaltic pump, anion exchange column, and effluent collection tank.

experiment. If not removed before assay, this interstitial, nonsorbed plutonium could easily be confused with legitimately sorbed plutonium. Complete removal of all nonsorbed plutonium from the column therefore was essential.

Column Rinsing Technique. We employed a rather lengthy washing procedure to remove any remaining nonsorbed plutonium. The residual feed solution first was removed by vacuum applied to the lower outlet of the column. Vacuum next was applied to the top of the column while it was being refilled from the bottom with clean $7 \mathrm{M}$ nitric acid. The purpose of this vacuum was to remove entrapped air that otherwise could prevent the column from completely refilling with liquid. Vacuum then was reapplied to the lower outlet to again drain the column of solution. And finally, this entire vacuum-filling/vacuumdraining process was repeated. All rinse solutions were combined and uniformly mixed with the previously collected effluent solution.

In this manner each loaded column was thoroughly drained of residual feed solution and rinsed twice with fresh nitric acid. We believe that this elaborate rinsing procedure removed not only all nonsorbed plutonium, but also a small portion of the legitimately sorbed plutonium. If so, this would contribute a negative bias, which would result in the reported resin capacities being somewhat understated. 


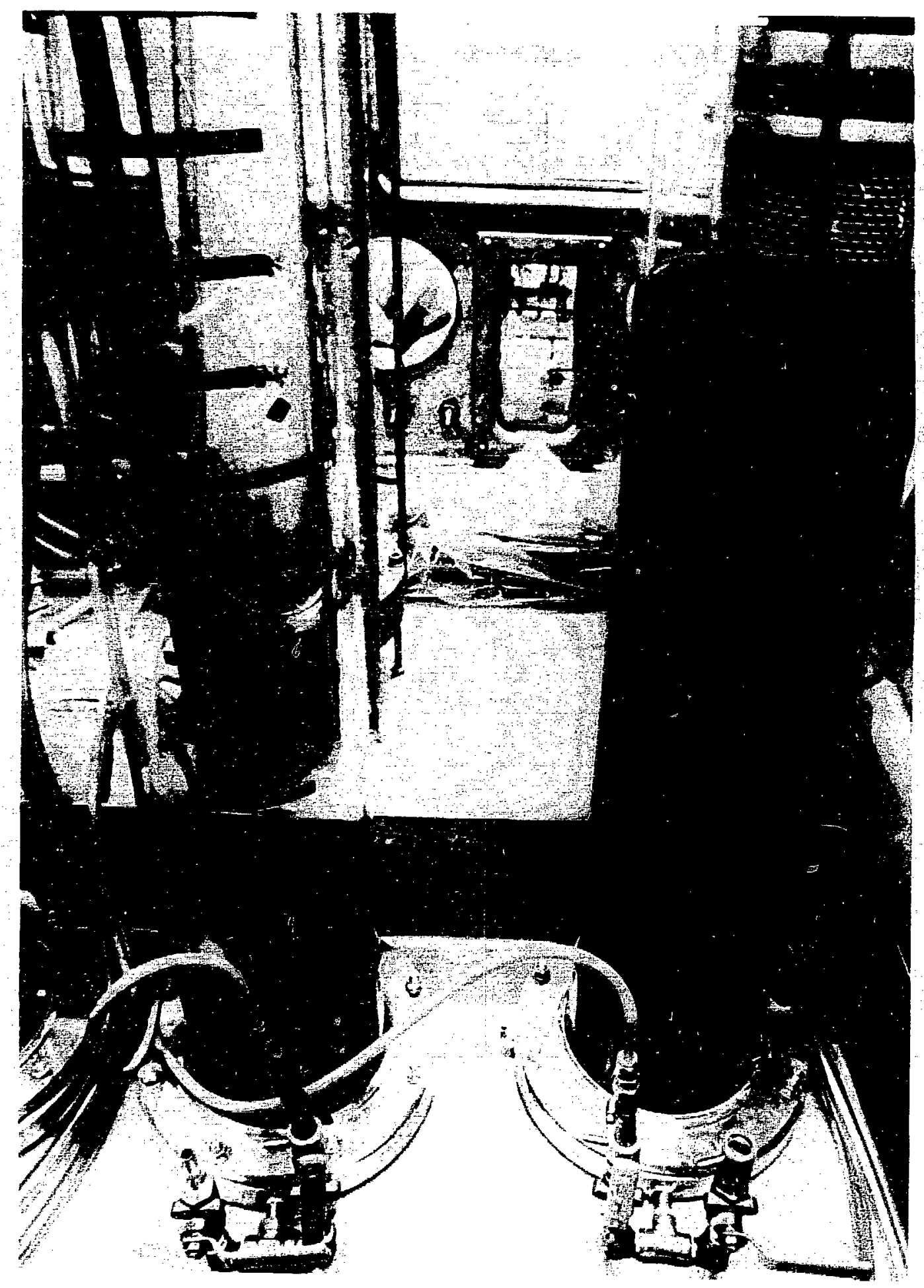

Fig. 4. Dual feed-solution tanks containing plutonium nitrate solution, as installed in glove box. 


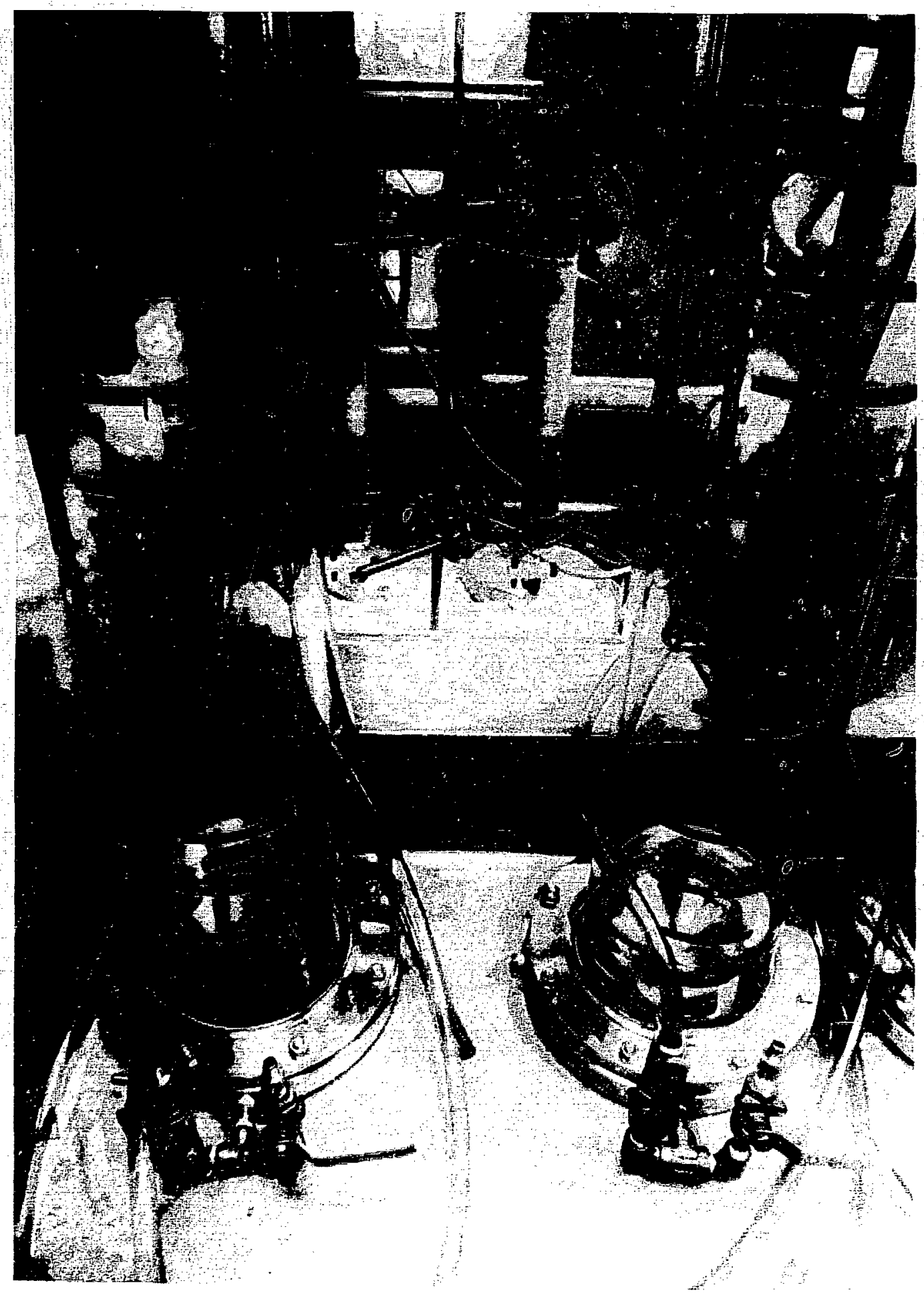

Fig. 5. Dual effluent collection tanks (foreground) during loading of anion exchange columns (background). 


\section{RESULTS AND DISCUSSION}

The flow rates used in these reduced-scale experiments were proportionately lower than flow rates for full-scale columns. All flow rates reported, however, have been readjusted to be directly applicable to the 6 -inch by 24-inch columns used in full-scale plant processes. We also report measured resin capacities in grams of plutonium per liter of resin to be applicable to columns of any size.

\section{Phase I: Low-Salt Solutions}

Table I presents the measured quantities of plutonium sorbed, per liter of Lewatit MP-500-FK resin, for each of 16 combinations of plutonium concentration and solution flow rate. Figure 6 presents these same data graphically. Two major conclusions are immediately apparent from these data: (1) there is essentially no flow rate dependence over the range of 10 to 80 liters per hour for the plutonium concentrations studied, and (2) the highest saturation loading of the resin occurs with solutions of the highest plutonium concentration.

Effect of Plutonium Concentration. As stated earlier, our findings using macroporous resin are in sharp contrast with those of earlier studies that used gel-type anion exchange resins. For example, Ryan and Wheelwright reported that plutonium concentration has little effect on resin capacity, ${ }^{3}$ whereas our data show a marked effect of plutonium concentration on the effective capacity of macroporous resin. Of particular importance is our finding that macroporous resin capacity is highest when plutonium concentration of the feed solution also is highest.

TABLE I. Quantity of Plutonium Sorbed by Lewatit MP-500-FK Resin from Low-Salt $7 \mathrm{M}$ Nitric Acid.

\begin{tabular}{ccccc}
\hline $\begin{array}{c}\text { Plutonium } \\
\text { Concentration } \\
\text { (grams/liter) }\end{array}$ & \multicolumn{4}{c}{$\begin{array}{c}\text { Flow Rate } \\
\text { (liters of solution per hour) }\end{array}$} \\
\cline { 2 - 5 } & 10 & 20 & 40 & 80 \\
\hline & \multicolumn{4}{c}{$\begin{array}{c}\text { Sorbed Plutonium } \\
\text { (grams per liter of resin) }\end{array}$} \\
\cline { 2 - 5 } 10 & 125 & 125 & 125 & 123 \\
20 & 140 & 138 & 139 & 140 \\
50 & 152 & 150 & 156 & 147 \\
110 & 168 & 170 & 167 & 167 \\
\hline
\end{tabular}

James $^{9}$ predicted earlier breakthrough of solutions that contain high concentrations of plutonium from columns of Dowex 1x4, per mole of plutonium fed to the column, because under these conditions a given amount of plutonium has a shorter column residence time. Yet our data and visual observations during the experiments consistently demonstrate quite the opposite - that breakthrough is delayed and the effective column capacity is highest when the feed solutions contain the highest concentrations of plutonium.

Why do our data differ so markedly from those of other studies? The most obvious reason is that we used a different resin, one that offers much faster sorption kinetics for plutonium. ${ }^{2}$ Rapid sorption kinetics would be expected to be most beneficial when the ratio of plutonium ions to the number of available resin exchange sites is high.

Another reason our findings differ from those of other studies, as mentioned earlier, is that our solutions that contain the highest concentrations of plutonium also contain the highest concentrations of nitrate. For example, solutions that contain 10 grams of plutonium per liter are approximately $0.04 \mathrm{M}$ in plutonium. If, as we assume, four nitrate ions associate with every $\mathrm{Pu}(\mathrm{IV})$ ion, the associated nitrate molarity is $0.16 \mathrm{M}$. By comparison, solutions that contain 120 grams of plutonium per liter have an associated nitrate concentration of $2.00 M$. The additional nitrate present as plutonium nitrate salt might very well enhance the distribution coefficient of $\mathrm{Pu}(\mathrm{IV})$, an effect that has been observed and reported for other dissolved nitrate salts.

James $^{10}$ reported that plutonium can be efficiently sorbed from solutions of only $4 M$ nitric acid if $0.3 M$ aluminum nitrate also is present. Ryan and Wheelwright ${ }^{11}$ reported much higher equilibrium distribution coefficients for plutonium from solutions that contained high concentrations of calcium nitrate. These higher distribution coefficients, however, took much longer to achieve because the plutonium sorption rate was much slower from high-nitrate-salt solutions. Over all, these investigators concluded that the disadvantage of lower sorption rate more than offset the eventual advantage of higher distribution coefficients.

Effect of Solution Flow Rate. Figure 6 shows that the saturation capacity of Lewatit MP -500-FK resin for the four plutonium concentrations studied is essentially unaffected when flow rates vary over the range of 10 to 80 liters per hour. This finding also is contrary to findings of previous studies with other anion exchange resins. Calleri and coworkers ${ }^{12}$ reported that adsorption of $\mathrm{Pu}(\mathrm{IV})$ on Permutit SK resin is 


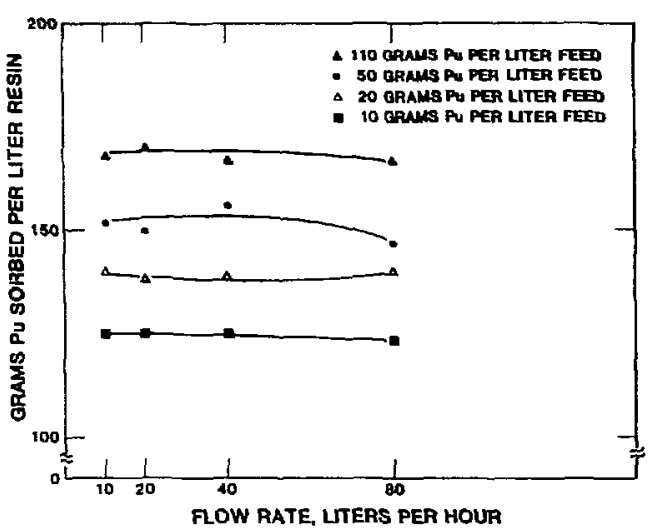

Fig. 6. Quantities of plutonium sorbed per liter of Lewatit MP-500-FK resin from low-salt solutions, for designated flow rates and plutonium concentrations. (Flow rates are scaled for a 6 -inch by 24 -inch column.)

inversely proportional to the solution flow rate but independent of plutonium concentration in the range of 0.8 to 5.5 grams per liter. Calleri found that breakthrough occurred more rapidly, and also that the effective resin capacity for plutonium was less at higher solution loading rates.

Again it seems likely that the rapid kinetics of Lewatit MP-500-FK resin explains its improved capacity, in comparison with the capacities of inferior resins examined in previous investigations. It is particularly noteworthy that many of these earlier studies used Permutit SK resin, which, although no longer manufactured, is considered by knowledgeable investigators to have been the best resin then available for plutonium. ${ }^{13}$

Resin Capacity. Our measured saturation capacities for Lewatit MP-500-FK resin can be compared with those reported for other resins. Basso" measured the saturation capacities of Amberlite IRA-938 and Dowex 11 resins to be 52 and 28 grams of plutonium per liter of resin, respectively. Calleri and coworkers found Permutit SK resin to have a capacity of $79 \pm 13$ grams of plutonium per liter of resin. 14 Calleri et al. ${ }^{12}$ state, "For all measurements made, the resin capacity was determined to be very close, but never higher than the capacity that it has for divalent $\mathrm{Pu}\left(\mathrm{NO}_{3}\right)_{6}=$."

The differences between these cited findings and our own were sufficient to justify a rigorous comparison of our measured capacities to the total resin capacity. The capacity of macroporous anion exchange resin usually is given as a nominal 1.2 equivalents per liter of resin. Rather then accept this value of uncertain origin, we converted a measured volume of nitrate-form
Lewatit MP-500-FK resin completely to the hydroxide form, washed the resin free of residual base with deionized water, and then determined the hydroxide content by acid-base titration.

To completely neutralize the hydroxyl ions, we added a measured excess of nitric acid to the hydroxideform resin. This resin/solution mixture was stirred overnight (in a sealed container) to ensure that all exchange sites would be neutralized. The quantity of excess nitric acid then was determined by back-titration with standard sodium hydroxide solution to a phenolphthalein endpoint.

The total capacity of the Lewatit MP-500-FK resin measured in this manner was 0.96 equivalents per liter of nitrate-form resin. If we assume that plutonium is sorbed on the resin in the form of a divalent hexanitrato anionic complex, as reported by Ryan, ${ }^{15}$ the maximum capacity for plutonium should be half of 0.96 , or 0.48 moles of plutonium per liter of resin, which corresponds to 115 grams of plutonium per liter of resin.

The fact that we measured plutonium loading capacities as high as 175 grams per liter of resin proves that all of the plutonium could not have been sorbed in a ratio of two anion exchange sites per plutonium ion, as had been proposed. ${ }^{13,14}$ Some plutonium ions (in fact most of them) may involve only a single anion exchange site. Another possibility involves a mechanism postulated by Kraus and Nelson ${ }^{16}$ whereby neutral plutonium nitrate species, such as $\mathrm{Pu}\left(\mathrm{NO}_{3}\right)_{4}$ or $\mathrm{H}_{2} \mathrm{Pu}\left(\mathrm{NO}_{3}\right)_{6}$, can diffuse into the resin at high solute concentrations.

Readers are-cautioned to carefully examine the mits used by other investigators who report resin capacities for plutonium. Some report capacities in weight of plutoninm per gram of $d r y$ resin, rather than per volume of wet resin. The choice of such units is difficult to understand, because dry-resil weight is unrelated to the capacity of an operating resin column. The fact that capacities computed on a dry-resin weight basis are approximately three- to fourfold higher than those computed on a wet-resin volume basis greatly adds to the opportunity for confusion.

\section{Phase II: High-Salt Solutiong}

The complete series of 16 combinations of plutonium concentration and flow rate studied in Phase I could not be repeated in the high-salt solutions examined in Phase I. This was because the highest concentration of plutonium (greater than 100 grams per liter) 
was not soluble in Phase II solutions that were nearly saturated with added nitrate salts. Phase II studies therefore were limited to the three lower concentrations of plutonium; however, each of these was evaluated at all four flow rates, for a total of 12 experınental combinations. The measured saturation capacities of Lewatit MP-500-FK resin for the 12 experimental combinations studied are listed in Table II and also are presented graphically in Fig. 7.

Effect of Plutonium Concentration. The range of measured resin capacities for Phase II solutions, when compared with that of Phase I solutions, is larger at low flow rates and smaller at high flow rates. We believe the trends shown in Fig. 7 result from a combination of the higher equilibrium distribution coefficients of plutonium and the slower sorption kinetics that occur from high-nitrate-salt solutions.

Adding to the complexity of this system is the presence of fluoride. In Phase II solutions, the concentration of fluoride $(0.093 M)$ is constant and equal to that of aluminum. However, because the concentration of plutonium varies in different experiments, the fluoride-to-plutonium ratio changes as the concentration of plutonium changes.

A recent Los Alamos study of the effect of varying ratios of Euoride to aluminum to plutonium ${ }^{6}$ demonstrated the importance of the overall fluoride-toplutonium ratio, as well as the fluoride-to-aluminum ratio. Because in Phase II solutions the fluoride concentration is constant, whereas the plutonium concentration varies, the solution that contains the highest plutonium concentration also has the lowest fluorideto-plutonium ratio. This may explain the highest measured capacity of $\mathbf{1 7 5}$ grams of plutonium per liter

TABLE II. Quantity of Plutonium Sorbed by Lewatit MP-500-FK Resin from Low-Salt $7 M$ Nitric Acid. ${ }^{a}$

\begin{tabular}{ccccc}
$\begin{array}{c}\text { Plutonium } \\
\text { Concentration } \\
\text { (grams/liter) }\end{array}$ & \multicolumn{4}{c}{$\begin{array}{c}\text { Flow Rate } \\
\text { (liters of solution per hour) }\end{array}$} \\
\cline { 2 - 5 } & 10 & 20 & 40 & 80 \\
\hline & \multicolumn{4}{c}{$\begin{array}{c}\text { Sorbed Plutonium } \\
\text { (grams per liter of resin) }\end{array}$} \\
\cline { 2 - 5 } 10 & 124 & 127 & 134 & 128 \\
20 & 136 & 140 & 140 & 136 \\
50 & 175 & 158 & 151 & 143
\end{tabular}

${ }^{a}$ In addition to $7 \mathrm{M}$ nitric acid, these solutions contained $0.69 \mathrm{M} \mathrm{Ca}\left(\mathrm{NO}_{3}\right)_{2}, 0.76 \mathrm{M} \mathrm{Mg}\left(\mathrm{NO}_{3}\right)_{2}, 0.093$ $M \mathrm{Al}\left(\mathrm{NO}_{3}\right)_{3}$, and $0.093 M$ fluoride.

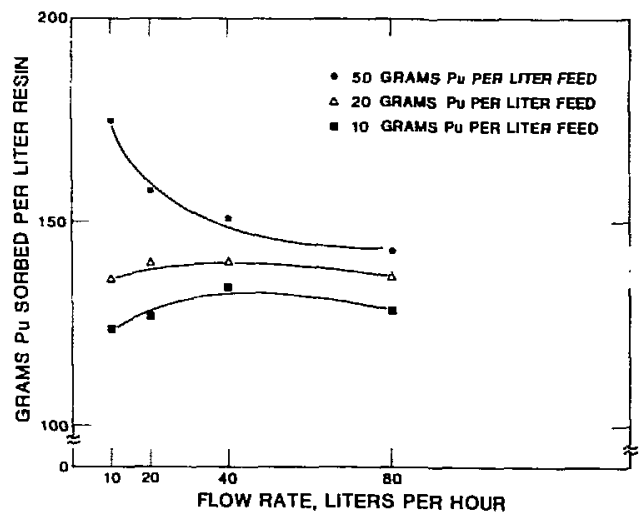

Fig. 7. Quantities of plutonium sorbed per liter of Lewatit MP-500-FK resin from high-salt solutions, for designated flow rates and plutonium concentrations. (Flow rates are scaled for a 6 -inch by 24-inch column.)

of resin measured for the 50-gram-per-liter Phase II solution at the lowest flow rate. This solution has not only the lowest fluoride-to-plutonium ratio, but also the highest total nitrate concentration of 11:01 $M$, which is the sum of $7 M$ nitric acid plus $3.18 M$ nitrate from the added impurity salts plus $0.83 M \mathrm{ni}-$ trate associated with $\mathrm{Pu}(\mathrm{IV})$ at 50 grams of plutonium per liter.

Effect of Solution Flow Rate. Earlier studies ${ }^{10,11}$ have reported that the high concentrations of nitrate salts that favor high sorption of plutonium at equilibrium significantly slow the sorption rate. This could explain the unusually high capacity of the resin for plutonium observed at the lowest flow rate for the high-salt solution having the highest plutonium concentration. However, an identical solution did not demonstrate unusually high resin capacity at higher flow rates, because at higher flow rates the plutonium residence time in the anion exchange column may be insufficient for the slower kinetics of the highsalt solutions to contribute.

Resin Capacity. It should be noted that the measured resin capacities for the three Phase II solutions are essentially identical to those for Phase I solutions of the same plutonium concentration, with a single exception. The high-salt solution with the highest plutonium concentration ( 50 grams per liter) exhibits an unusually high resin capacity at the lowest flow rate ( 10 liters per hour). We consider this to be primarily an effect of flow rate, as described in the previous paragraph. 


\section{CONCLUSIONS}

1. Lewatit MP-500-FK resin offers substantially higher saturation capacities for $\mathrm{Pu}(\mathrm{IV})$ from nitric acid than any resin previously studied.

2. The saturation capacity of Lewatit MP-500-FK resin for plutonium is highest for feed solutions that have the highest concentrations of plutonium, in contrast to results reported from previous studies of other resins.

3. Flow-rate variation has essentialiy no effect on the saturation capacity of a 6 -inch by 24 -inch column of Lewatit MP-500-FK resin for plutonium from lowsalt solutions of plutonium within the range of 10 to 80 liters per hour. Flow rate has a significant effect, however, when solutions with high plutonium concentrations contain high levels of nitrate salts. In such solutions, low flow rates increase the effective resin capacity, whereas high flow rates do not decrease it. As explained earlier, this is attributed to the need for a longer residence time within the column to take advantage of the higher distribution of plutonium for highsalt solutions.
4. Advantages of Lewatit MP-500-FK resin over gel-type resin for processing plutonium include faster sorption kinetics, ${ }^{2}$ higher resin capacity in general, higher resin capacity at high concentrations of plutonium, little or no effect from an eightfold increase in flow rate, and little degradation in períormance when solutions approach the saturation level in impurity nitrate salts.

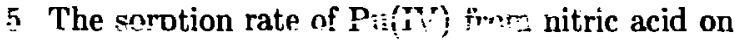
Lewatit ivis-jul-FK resin is sufficiently rapid to have not been a limiting factor for the range of flow rates and plutonium concentrations included in this study. Future studies of higher plutonium concentrations and faster flow rates, although unrealistic for process-scale applications, could contribute to a better understanding of plutonium sorption kinetics and mechanisms.

\section{ACKNOWLEDGMENTS}

We gratefully acknowledge the useful technical discussions with and suggestions of Jeff Hatchell and Arch Nixon. 


\section{REFERENCES}

1. "Los Alamos Standard Operating Procedure for Nitrate Anion Exchange," procedure 461-REC-R02, Los Alamos National Laboratory internal document (March 1987).

2. S. F. Marsh, "Improved Recovery and Purification of Plutonium at Los Alams Using Macroporous Anion Exchange Resin," Los Alamos National Laboratory report LA-10946 (May 1987).

3. J. L. Kyan and E. J. Wheelwright, "Recovery, Purification, and Concentration of Plutonium by Anion Exchange in Nitric Acid," U. S. Atomic Energy Commission report HW-55893(Del.), p. 39 (January 1959).

4. D. L. Basso, "Evaluation of Amberlice IRA-938 and Dowex 11 Anion Exchange Resins on a Pilot Plant Scale," Rockwell Internationai Rocky Flats Plant report CHOP-9202-83-11 (October 1983).

5. S. F. Marsh and T. D. Gallegos, "Chemical Treatment of Plutonium with Hydrogen Peroxide Before Nitrate Anion Exchange Processing," Los Alamos National Laboratory report LA-10907 (May 1987).

6. S. F. Marsh, "The Effect of Fluoride and Aluminum on the Anion Exchange of Plutonium from Nitric Acid," Los Alamos National Laboratory report LA10999 (July 1987).

7. J. D. Navratil, "Evaluation of Anion Exchange Resins for Plutonium-Uranium Separations in Nitric Acid," J. Radioanal. Chem. 43, 31-35 (1978).

8. J. D. Navratil and L. L. Martella, "Comparison of Anion Exchange Resins for Recovering Plutonium from Nitric Acid Waste," Nucl. Technol. 46, 105109 (1979).
9. D. B. James, "Processing of Plutonium by Ion Exchange-VI. Plutonium(IV) Sorption Kinetics on Dowex 1x4 from Nitrate Solutions," Los Alamos Scientific Laboratory report LA-DC-7066, Figure 9 (July 1965).

10. D. B. James, "The Processing of Plutonium by Ion Exchange-V. Equilibrium Anion-Exchange Sorption from Mixed Nitric Acid-Aluminum Nitrate Solvents," Los Alamos Scientific Laboratory 1eport LA-3188 (March 1965).

11. J. L. Ryan and E. J. Wheelwright, "Recovery and Purification of Plutonium by Anion Exchange," Ind. Eng. Chem. 51(1), 60-65 (1959).

12. G. Calleri, A. Geoffroy, F. Franssen, and M. Demonie, "Study of the Kinetics of Loading Pu(IV) on Permutit SK Resin from 7.2 $\mathrm{M}$ Nitric Acid," Eurochemic Technical Report No. 120 (NP-12345), (September 1961).

13. J. L. Ryan and E. J. Wheelwright, personal communication (May 1986).

14. G. Calleri, A. Geoffroy, F. Franssen, and J. Demonie, "Study of the Kinetics of Pu(IV) Elation from Permutit SK Resins, $40-70$ mesh, at $60^{\circ} \mathrm{C}$ by $0.6 M$ Nitric Acid," Eurochemic Technical Report No. 125 (NP-12244), (September 1961).

15. J. L. Ryan, "Species Involved in the AnionExchange Absorption of Quadrivalent Actinide Nitrates," J. Phys. Chem. 64, 1375-1385 (1960).

16. K. A. Kraus and F. Nelson, "Anion Exchange Studies of Metal Complexes," Chapter 23 in The Struciure of Electrolyte Solutions, W. J. Hamer, Ed. (J. Wiley and Sons, Inc., New York, 1959), pp. 340364. 